\title{
Efficacy and Safety of Pravastatin in the Long-term Treatment of Elderly Patients With Hypercholesterolemia
}

\author{
John T. Santinga, MD, Ann Arbor, Michigan, Howard S. Rosman, MD, Melvyn Rubenfire, MD, \\ James J. Maciejko, MS, PhD, Lester Kobylak, MD, Detroit, Michigan, Mark E. McGovern, MD, \\ Bruce D. Behounek, MD, Princeton, New Jersey
}

PURPOSE: Elevated cholesterol levels are a major risk factor for coronary heart disease, which remains a significant problem in patients beyond age 65 years. Because drug therapy for the control of hypercholesterolemia in elderly patients is frequently considered to be indicated, we investigated the efficacy and safety of pravastatin in the treatment of elderly subjects with primary hypercholesterolemia.

PATIENTS AND METHODS: In this 96-week, multicenter, double-blind, placebo-controlled study, 142 subjects (95 women, 47 men) 64 to 90 years of age with elevated cholesterol levels despite dietary intervention were randomized to receive pravastatin $20 \mathrm{mg}$ at bedtime or matching placebo (2:1). Dosage could be doubled after 8 weeks, a bile acid-binding resin could be added after 16 weeks, and nicotinic acid or probucol could be added after 32 weeks, as needed, to adequately lower the low-density lipoprotein cholesterol (LDL-C) levels.

RESULTS: Significant reductions in the levels of LDL-C (-30.9\%), total cholesterol (Total-C; $-21.9 \%$ ), and triglycerides (TG; $-16.7 \%$ ) and significant increases in the levels of high-density lipoprotein cholesterol (HDL-C; $\mathbf{1 1 . 3 \% )}$ were noted in the group receiving pravastatin treatment at 16 weeks ( $P \leq 0.001$ compared with baseline, $P \leq 0.01$ compared with placebo). The cholesterol-lowering effects of pravastatin were sustained throughout the 96 weeks of the trial. Pravastatin was well tolerated, with an overall incidence of adverse events nearly identical to that of placebo.

CONCLUSIONS: In this study, pravastatin was well tolerated and effective in lowering LDL-C, Total-

From the Division of Geriatric Medicine (JTS), University of Michigan Hospitals, Ann Arbor, Michigan, the Department of Internal Medicine (HSR, LK), Henry Ford Hospital, Detroit, Michigan, the Department of Medicine (MR, JJM), Sinai Hospital of Detroit, Detroit, Michigan, and Bristol-Myers Squibb Pharmaceutical Research Institute (MEM, BDB), Princeton, New Jersey.

This study was supported by a grant from the Bristol-Myers Squibb Company, Princeton, New Jersey.

Requests for reprints should be addressed to John T. Santinga, MD, Division of Geriatric Medicine, 300 North Ingalls Building, University of Michigan Hospitals, Ann Arbor, Michigan 48109-0405.

Manuscript submitted February 9, 1993, and accepted in revised form October 22, 1993.
$C$, and TG and in raising HDL-C during long-term treatment of elderly patients with primary hypercholesterolemia.

The complications of atherosclerosis, including 1 coronary heart disease (CHD), are the leading cause of death in most developed nations. Elevated low-density lipoprotein (LDL-C) and total cholesterol (Total-C) levels, as well as low levels of highdensity lipoprotein cholesterol (HDL-C), are directly related to atherogenesis and are major risk factors for CHD. ${ }^{1-4}$ The prevalence of hypercholesterolemia and frequency of CHD increase with age, and the correlation between elevated lipid levels and CHD appears to persist after age $65 .{ }^{5,6} \mathrm{~A}$ clear relationship between lowering cholesterol levels and a reduction in cardiovascular morbidity and mortality in elderly patients with hypercholesterolemia has yet to be affirmed in controlled studies, and the overall benefit of lipid-lowering therapy in this population has not yet been determined. Maintaining a balanced, fatrestricted diet can be difficult in the elderly, and inconvenient dosage forms and unpleasant side effects have long hindered compliance with previously available lipid-lowering drugs in this population. The 3-hydroxy-3-methylglutaryl coenzyme A (HMG CoA) reductase inhibitors, with once-daily dosing and improved safety profiles, offer the potential for greater patient compliance and a more favorable balance of the risk of adverse effects versus the expected benefits of therapy.

Pravastatin, a hydrophilic IIMG CoA reductase inhibitor, has been shown to be effective and well tolerated in extensive clinical trials involving more than 27,000 hypercholesterolemic subjects, including more than 15,000 taking the drug, some for up to 7 years or more..$^{7-9}$ By inhibiting cholesterol synthesis in the hepatocyte, increasing LDL receptor activity and number, and facilitating LDL uptake, ${ }^{10-12}$ pravastatin produces dose-related reductions of up to $30 \%$ to $34 \%$ in levels of LDL-C, $22 \%$ to $27 \%$ in levels of Total-C, and $10 \%$ to $25 \%$ in levels of triglycerides (TG) and increases of $4 \%$ to $12 \%$ in the levels of HDL C. $7,8,13,14$ In comparative studies in primarily middleaged subjects, pravastatin has proved an acceptable alternative to nicotinic acid,,${ }^{15}$ probucol, ${ }^{16}$ fibric acid derivatives, ${ }^{17-19}$ and bile-acid sequestrants. ${ }^{20}$ The goal of the present study was to evaluate the use of 
pravastatin in the long-term treatment of elderly subjects with primary hypercholesterolemia.

\section{PATIENTS AND METHODS}

\section{Subject Selection}

Eligible subjects were men and women 65 years of age or older with primary (Type II) hypercholesterolemia. Potential subjects with elevated cholesterol levels were identified in medical clinics at the participating institutions and referred to a dietician for counseling. After at least 6 weeks on a low-fat, low-cholesterol diet, the mean of two consecutive determinations of fasting plasma LDL-C concentration was required to be greater than the 95th percentile for the corresponding age and gender group of the US population $^{21}(165 \mathrm{mg} / \mathrm{dL}$ for men or above $170 \mathrm{mg} / \mathrm{dL}$ for women), and the mean TG concentration in the same specimens was to be less than $250 \mathrm{mg} / \mathrm{dL}$. Subjects with homozygous familial hypercholesterolemia, Type I, III, IV, or V hyperlipoproteinemia, or significant endocrine, renal, hepatic, metabolic, or cardiovascular disease were excluded, as were those taking medication (eg, corticosteroids, thiazide diuretics, beta-adrenergic blockers) that might affect lipid levels. Women receiving a stable dose of conjugated estrogens were eligible. Subjects were required to give informed written consent both at the beginning of the initial 48-week study and the 48-week extension phase. The protocol was approved by the institutional review boards of the three study centers.

\section{Study Design}

'This clinical trial was a randomized, double-blind, parallel, placebo-controlled examination of the efficacy and safety of pravastalin in elderly subjects with primary hypercholesterolemia inadequately responsive to dietary intervention. With counscling by dietitians, a low-fat, low-cholesterol, eucaloric diet, equivalent to the American Heart Association Phase I, was started 6 weeks or more before blood was drawn for the qualifying lipid evaluations. This diet was continued throughout the trial and periodically evaluated at clinic visits by means of a 3-day food record. Subjects were instructed not to otherwise change their lifestyles (eg, start an exercise program) during the study. Any lipid-lowering medications were discontinued at least 9 weeks before randomization. After a dietary stabilization period of 7 to 14 weeks, subjects who qualified were randomly assigned to one of two treatment groups, pravastatin $20 \mathrm{mg}$ at bedtime or placebo, in a 2:1 ratio. The short-term treatment phase was 16 weeks in duration. After completing the initial 8 weeks, a treatment decision was made for all subjects dependent upon their week 8 LDL-C results, with blinded therapy increased from $20 \mathrm{mg}$ at bedtime to $40 \mathrm{mg}$ at bedtime if the subject's LDLrC concentration was still above the 95th percentile. After 16 weeks of double-blind therapy in the short-term phase, if the LDL-C concentration remained above the 75 th percentile, a bile acid-binding resin could be added to the regimen of subjects in either treatment group at the beginning of the long-term phase of the study. Later, in the long-term phase, nicotinic acid or probucol could be added as needed to attempt to reduce LDL $\mathrm{C}$ levels below the 75th percentile. The initial 18-week study was followed by a 48-week extension period, with the treatment regimen to remain as it was in the final 16 weeks of the first year.

\section{Clinical Safety and Laboratory Evaluation}

Subjects returned to the clinic at 2- to 6-week intervals throughout the trial. Health status, interim illnesses, and the use of non-study drugs were evaluated and recorded at each clinic visit. Comprehensive physical examinations, clinical tests, and dietary compliance evaluations were performed at specified intervals. Clinical adverse events, defined as any new or worsening illnesses, signs, or symptoms, and compliance with study drug, as determined by counting the remaining supply of tablets, were assessed at each clinic visit.

Lipid analyses were performed by the Lipid Research Laboratory, Sinai Hospital of Detroit, which is certified by the Centers for Disease Control/National Heart, Lung and Blood Institute Standardization Program. Concentrations of Total-C and TG were determined using standard enzymatic procedures. Levels of HDL $\mathrm{C}$ were determined after precipitation of apolipoprotein $\mathrm{B}$ containing lipoproteins with dextran sulfate- $\mathrm{MgCl}_{2}$. The $\mathrm{LDL}-\mathrm{C}$ values were calculated using a variation of the Friedewald formula described by Delong: LDLC $=$ Total-C $-(0.16$ TG + HDL-C $) .{ }^{22}$

Bascline clinical safety assessments, including a complete medical history, a physical examination, a 12 lead electrocardiogram, a complete ophthalmologic examination (including slit-lamp examination and lens opacity grading), and a chest roentgenogram (if a film taken in the previous 3 months was not on file), were completed within the dietary stabilization/lead-in period. Laboratory safety tests included hematology (complete blood count, including differential), clinical chemistry, and urinalysis on a freshly voided morning specimen (with microscopic examination of the sediment if the dipstick results were positive for blood or white blood cells) at each clinic visit; serum thyroxine $\left(\mathrm{T}_{4}\right)$ determination at baseline and at weeks 16 and 48; and a stool test for occult blood at baseline and at weeks 8,16 , and 48 . The laboratory tests were performed by SmithKline Beecham Clinical Laboratories (Van Nuys, CA) employing quality assurance procedures in accordance with standards required by the US government agencies licensing clinical laboratories. 


\section{Statistical Analysis}

The two treatment groups were compared for homogeneity of baseline measures. Efficacy parameters were analyzed after logarithmic transformations resulting in normality and homogeneity of variance. Model assumptions were assessed by Shapiro-Wilk-Wtest and Levene's test. Analyses of covariance were performed on the natural logarithms of the follow-up visit value and the baseline value with treatment and investigator as model effects and logarithmic value of baseline measure as a covariate. The statistical significance tests were performed for between- and within-group comparisons, and $P$-values were determined for short-term visits only. For the long-term period, only within-group comparisons were made, and $95 \%$ confidence limits without $P$-values were reported. Within-group changes from baseline were assessed through a paired t-statistic using the least squares means and mean squared error from the linear model above. The $95 \%$ confidence limits for the mean percent changes, adjusted for baseline differences and numerical imbalances among investigators, wcre obtained by exponentiating their upper and lower confidence limits in the logarithmic scale. The results of the analyses were summarized by arithmetic means, standard deviations, and adjusted percent changes from baseline with $95 \%$ confidence limits.

\section{RESULTS}

A total of 142 patients were randomized. All 142 patients received study medication and were included in the safety database; however, 1 patient discontinued prior to any efficacy data being obtained in the

\begin{tabular}{|c|c|c|c|}
\hline \multicolumn{4}{|l|}{ TABLE I } \\
\hline \multirow[b]{2}{*}{ Variable } & \multicolumn{3}{|c|}{ Treatment Group } \\
\hline & $\begin{array}{c}\text { Pravastatin } \\
(\mathrm{n}=93)\end{array}$ & $\begin{array}{l}\text { Placebo } \\
(n=48)\end{array}$ & $\begin{array}{c}\text { Total } \\
\langle\mathrm{n}=141\}\end{array}$ \\
\hline \multicolumn{4}{|l|}{$\overline{\operatorname{Sex}}$} \\
\hline Male & $33(35 \%)$ & $14(29 \%)$ & $47(33 \%)$ \\
\hline Female & $60(65 \%)$ & $34(71 \%)$ & $94(67 \%)$ \\
\hline \multicolumn{4}{|l|}{ Age (years) } \\
\hline Mean & 70.3 & 70.8 & 70.5 \\
\hline$S D$ & 4.8 & 5.7 & 5.1 \\
\hline Range & $64-86$ & $65-90$ & $64-90$ \\
\hline \multicolumn{4}{|l|}{ Race } \\
\hline White & $73(78 \%)$ & $33(69 \%)$ & $106(75 \%)$ \\
\hline Black & $20(22 \%)$ & $14(29 \%)$ & $34(24 \%)$ \\
\hline Oriental & $0(0.0 \%)$ & $1(2.1 \%)$ & $1(0.7 \%)$ \\
\hline \multicolumn{4}{|c|}{ Lipids (mg/dL) } \\
\hline LDL-C & 199.0 & 207.9 & 202.0 \\
\hline Total-C & 272.2 & 278.7 & 274.4 \\
\hline HDL-C* & 50.4 & 45.9 & 48.9 \\
\hline $\mathrm{TG}$ & 112.6 & 155.5 & 147.0 \\
\hline
\end{tabular}

- Significant difference between treatment groups at baseline $(P \leq 0.05)$. $L D L-C=$ low-density lipoprotein cholesterol; Total $-C=$ total cholesterol: HDL-C = high-density lipoprotein cholesterol; $T G=$ triglycerides.

active-treatment phase, leaving 141 subjects in the intent-to-treat population (all randomized subjects who had at least one follow-up visit with efficacy determination). Of the 141 patients, 136 completed the first 16 weeks of the study, 114 completed the next 32 weeks, and 96 completed 96 weeks.

As shown in Table I, the intent-to-treat population included more women $(94$, or $67 \%)$ than men $(47$, or $33 \%$ ), had an overall mean age of 70.5 years, and was

\begin{tabular}{|c|c|c|c|}
\hline \multicolumn{4}{|c|}{ Effect of Treatment on Lipid Values at Week 16} \\
\hline $\begin{array}{l}\text { Lipid/ } \\
\text { Treatment* }\end{array}$ & $\begin{array}{c}\text { Baseline (mg/dL) } \\
\text { Mean (SD) }\end{array}$ & $\begin{array}{c}\text { Week } 16(\mathrm{mg} / \mathrm{dL}) \\
\text { Mean (SD) }\end{array}$ & $\begin{array}{c}\% \text { Change }^{\dagger} \\
\text { Mean (95\% CL) }\end{array}$ \\
\hline \multicolumn{4}{|l|}{ LDL-C } \\
\hline Pravastatin & $198.4(23.6)$ & $138.7(24.4)$ & $-30.9 \ddagger(-33.1,-28.7)$ \\
\hline Placebo & $208.4(40.8)$ & $209.8(49.0)$ & $0.6(-3.7,5.17)$ \\
\hline \multicolumn{4}{|l|}{ Total-C } \\
\hline Pravastatin & $271.6(28.2)$ & $213.6(31.1)$ & $-21.9 \ddagger(-23.7,-20.0)$ \\
\hline Placebo & $279.2(42.8)$ & $281.9(49.3)$ & $0.9(-2.3,4.25)$ \\
\hline \multicolumn{4}{|l|}{ HDL-C } \\
\hline Pravastatin & $50.2(12.6)$ & $55.4(14.2)$ & $11.3^{5}(8.5,14.2)$ \\
\hline Placebo & $46.0 \quad(10.6)$ & $47.7(9.1)$ & $3.69(0.1,7.2)$ \\
\hline \multicolumn{4}{|l|}{$\mathrm{TG}$} \\
\hline Pravastatin & $144.1 \quad(41.5)$ & $121.8(39.1)$ & $-16.7 \S(-21.1,-12.1)$ \\
\hline Placebo & $154.5(46.1)$ & $152.2(70.0)$ & $-4.2(-11.1,3.2)$ \\
\hline \multicolumn{4}{|c|}{ 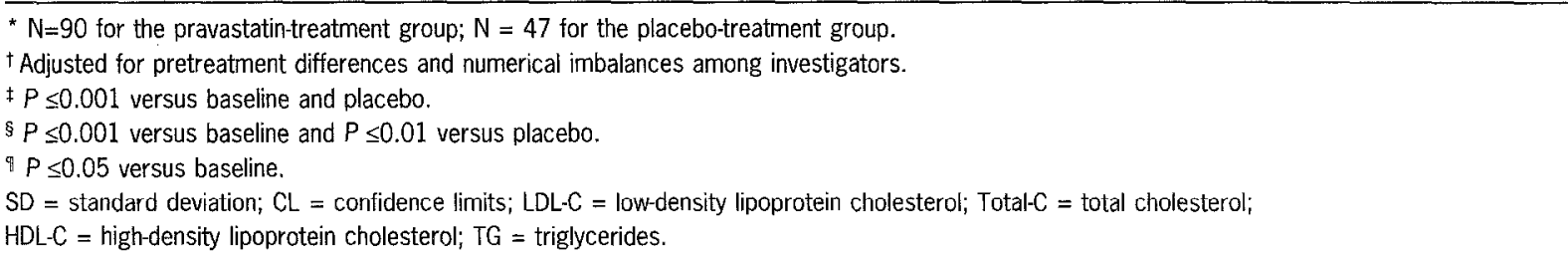 } \\
\hline
\end{tabular}




\section{LDL-Cholesterol}

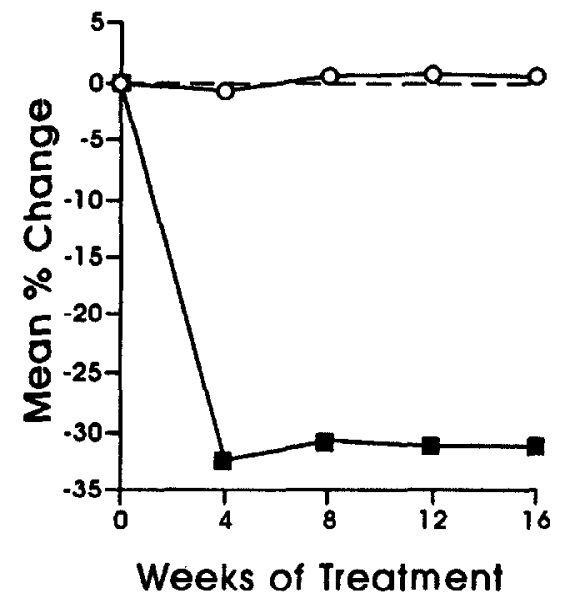

HDL-Cholesterol

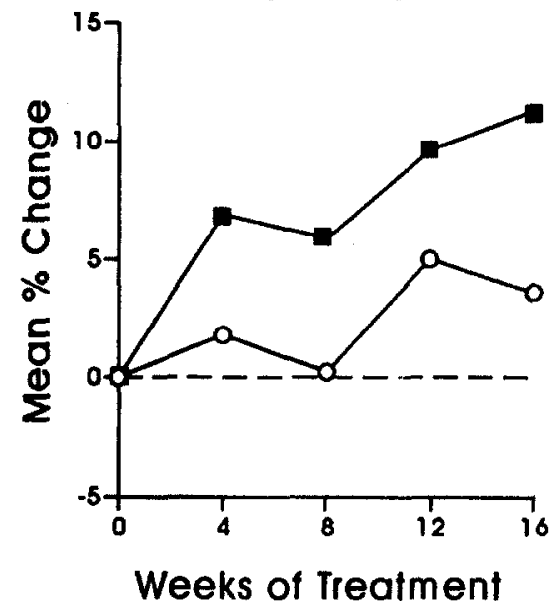

Total Cholesterol

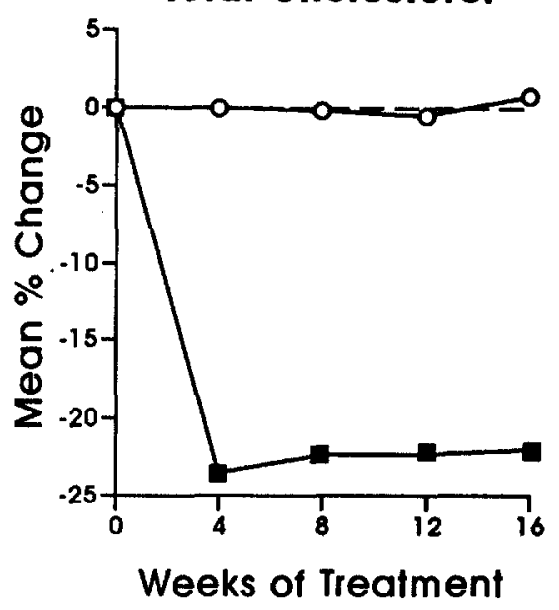

Triglycerides

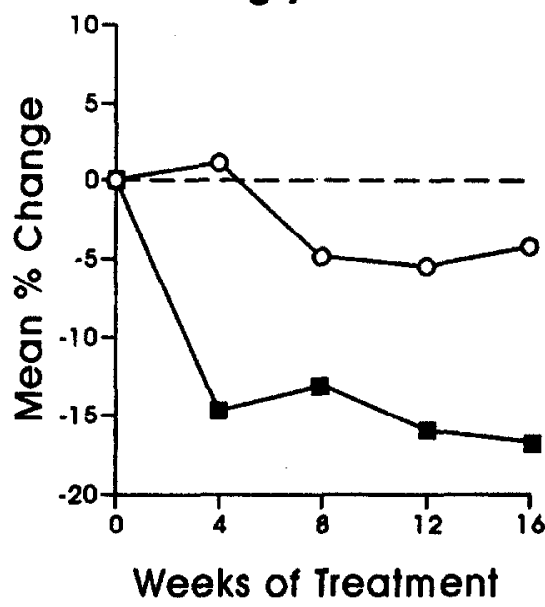

Figure. Adjusted mean percentage changes in lipid and lipoprotein values through the first 16 week phase of the study. LDL-cholesterol $=$ lowdensity lipoprotein cholesterol; HDL-cholesterol $=$ high-density lipoprotein cholesterol. predominantly white ( $75 \%)$. The median age of the study population was determined to be 69 years. With the exception of baseline $\mathrm{HDL}-\mathrm{C}$ values, no significant differences in the demographic characteristics between the two treatment groups were detected by a chi-square test of association or a linear model adjusted for numerical differences among investigators.

\section{Efficacy Analyses}

The primary efficacy criterion was the reduction at week 16 in fasting plasma $\mathrm{LDL}-\mathrm{C}$ levels from the baseline value. Changes in levels of Total-C, HDL-C, and TG were secondary efficacy criteria. After week 16, all subjects were eligible to be treated with additional lipid-lowering therapy. The average daily dose of pravastatin in the active-treatment group at week 16 was $20.4 \mathrm{mg}$, with only 1 of 88 patients in the pravastatin treatment group having the dose increased after the measurement of LDL-C at week 8 .

\section{Lipid and Lipoprotein Response}

The mean percentage changes in adjusted mean lipid values from baseline at week 16 are presented in Table II. The Figure plots the percentage changes in these parameters throughout the short-term phase.

Statistically significant decreases in LDL-C and Total-C were noted in the pravastatin-treatment group after 4 weeks of therapy ( $P \leq 0.001$ compared with baseline and placebo). These effects were sustained and remained significant at all timepoints for the duration of the 16-week pravastatin-placebo comparison period ( $P \leq 0.001$ compared with baseline and placebo). Mean percent elevations of HDL-C levels and mean percent reductions in $T G$ values with pravastatin therapy were significantly different from baseline and placebo at all timepoints in the first 16 weeks ( $P \leq 0.05$ to 0.001 ). At week 96 , the group originally assigned pravastatin had reductions in levels of LDL-C of $29.9 \%$, Total-C $20.2 \%$, and TG $9.0 \%$ and ele- 


\begin{tabular}{|c|c|c|c|c|}
\hline \multicolumn{5}{|c|}{$\begin{array}{l}\text { TABLE III } \\
\text { Most Common Adverse Events, Weeks } 1 \text { Through 16* }\end{array}$} \\
\hline \multirow[b]{2}{*}{ Adverse Event } & \multicolumn{4}{|c|}{ Number $(\%)$ of Subjects } \\
\hline & \multicolumn{2}{|c|}{$\begin{array}{l}\text { Pravastatin } \\
\text { (n=94) }\end{array}$} & \multicolumn{2}{|c|}{$\begin{array}{c}\text { Placebo } \\
(\mathrm{n}=48)\end{array}$} \\
\hline Musculoskeletal pain & 13 & $(13.8)$ & 6 & $(12.5)$ \\
\hline Upper respiratory infection & 11 & $(11.7)$ & 7 & (14.6) \\
\hline Headache & 7 & $(7.4)$ & 5 & $(10.4)$ \\
\hline Dizziness & 9 & (9.6) & 2 & (1.2) \\
\hline Cough & 7 & (7.4) & 3 & $(6.3)$ \\
\hline Flatulence & 6 & (6.4) & 4 & (8.3) \\
\hline Influenza & 7 & (7.4) & 3 & (6.3) \\
\hline Abnormal urination & 6 & (6.4) & 3 & (6.3) \\
\hline Fatigue & 4 & (4.3) & 5 & (10.4) \\
\hline Insomnia & 3 & (3.2) & 5 & (10.4) \\
\hline
\end{tabular}

*The events listed are the 10 most common events for both treatment groups, in decreasing order of frequency.

vations of levels of HDL-C by $11.6 \%$. The corresponding 96-week results for the group originally assigned placebo, but at this time receiving alternative therapy, were $18.8 \%, 13.7 \%, 0.1 \%$, and $3.5 \%$, respectively.

\section{Safety Results}

The evaluation of drug safety was conducted for the two distinct phases of the trial, the short-term (weeks 1 through 16) phase and the long-term (weeks 17 through 102) phase. Safety analyses were performed on the total randomized population. Although the study was 96 weeks in duration, some patients were evaluated up to 102 weeks after randomization.

Pravastatin was well tolerated in this study. Four of 142 subjects (2.8\%) discontinued treatment because of clinical adverse events during the first 16 weeks of the study, 3 of 94 (3.2\%) in the pravastatin group (generalized weakness, epigastric pain, and dizziness), and 1 of 48 (2.1\%) in the placebo group (skin rash). The frequencies of adverse events during the short-term phase were $26.6 \%$ and $33.3 \%$ for the pravastatin- and placebo-treatment groups, respectively. The 10 most common adverse events in the short-term phase are shown in Table III. There were no statistically significant differences between treatment groups in the frequency of these 10 events. There was one serious cardiovascular adverse event reported in the short-term, a case of angina leading to hospitalization in a subject receiving placebo. Four subjects (2.8\%) were withdrawn from the study during the first 16 weeks because of laboratory abnormalities, two (2.1\%) in the pravastatin group and two (4.2\%) in the placebo group. Of the two pravastatintreated subjects withdrawn, one had elevated $\gamma_{\text {-ghlu- }}$ tamyl transferase (GGT) and alkaline phosphatase values, and the second had proteinuria, as evidenced by dipstick reading. Of the two placebo-treated subjects withdrawn, one experienced elevations of ala-

\section{TABLE IV}

Most Common Adverse Events, Weeks 17 Through $102^{*}$

\begin{tabular}{lrrrr}
\hline & \multicolumn{3}{c}{ Number (\%) of Subjects } \\
\cline { 2 - 5 } Adverse Event & $\begin{array}{c}\text { Pravastatin } \\
\text { (n=89) }\end{array}$ & \multicolumn{2}{c}{$\begin{array}{c}\text { Placebo } \\
\text { (n=47) }\end{array}$} \\
\hline Musculoskeletal pain & 29 & $(32.6)$ & 13 & $(27.7)$ \\
Upper respiratory infection & 25 & $(28.1)$ & 6 & $(12.3)$ \\
Constipation & 4 & $(4.5)$ & 14 & $(29.8)$ \\
Dizziness & 8 & $(9.0)$ & 8 & $(17.0)$ \\
Abdominal pain & 7 & $(7.9)$ & 8 & $(17.0)$ \\
Diarrhea & 8 & $(9.0)$ & 7 & $(14.9)$ \\
Influenza & 13 & $(4.6)$ & 2 & $(4.3)$ \\
Nausea/vomiting & 6 & $(6.7)$ & 9 & $(19.1)$ \\
Vision distırbance & 12 & $(13.5)$ & 3 & $(6.4)$ \\
Pharyngitis & 11 & $(12.4)$ & 2 & $(4.3)$ \\
\hline
\end{tabular}

*The events listed are the 10 most common events for both treatment groups, in decreasing order of frequency. nine aminotransferase (ALT) and aspartate aminotransferase (AST) values, and the other had an asymptomatic decrease in white cells.

Eighteen of 136 subjects (13.2\%), 9 of 89 (10.1\%) pravastatin-treated subjects, and 9 of 47 (19.1\%) placebotreated subjects, discontinued due to an adverse event or a marked laboratory abnormality (predefined by the protocol) during the 80 -week long-term phase. There was a high frequency of adverse events in this elderly study population in both the pravastatin-treated group (96.6\%) and the placebo-treated group (95.7\%). The increases in discontinuates and the frequency of adverse events in the long-term phase are to be expected in light of the six-fold increase in length of exposure. The 10 most common events in the long-term phase are shown in Table IV. The syndrome of drug-induced myopathy (myalgia associated with increase in crealine kirlase more than 10 times the upper limit of normal) was not observed in any pravastatin-treatcd subject at any time during the trial. There were three serious cardiovascular adverse events involving cardiac ischemia reported in each treatment group during the long-term (3.4\% in the pravastatin group and $6.4 \%$ in the placebo group).

No statistically significant differences between treatment groups in the frequency of marked laboratory test abnormalities were noted in either the short-term or the long-term analyses. No significant changes from baseline or differences between groups were observed for mean creatine kinase values during the short-term phase. The pravastalin group showed statistically significant $(P \leq 0.05)$ increases in mean AST and ALT levels in the short term phase relative to both baseline and the placebo group, but these had no apparent clinical importance as they were small $(0.7$ to $2.4 \mathrm{u} / \mathrm{L})$ and did not result in mean values outside the normal range. During the long-term phase, the values for creatine kinase, AST, and ALT were similar to those observed in the short-term period. 
There was no difference between treatment groups in the overall incidence of lens opacity progression or in any of the individual lens parameters, except for cortical opacity, in which the control group experienced an unexplained improvement.

\section{COMMENTS}

Hypercholesterolemia remains a substantial problem in the elderly (patients more than 65 years of age), with one third of older men and one half of older women having serum cholesterol levels greater than $240 \mathrm{mg} / \mathrm{dL}^{21}$ Age is an additional risk factor for $\mathrm{CHD}$, with the prevalence, incidence, morbidity, and mortality of CHD increasing with advancing age..$^{23}$ There are distinct sex-related differences. For men, $\mathrm{CHD}$ increases rapidly after middle age, whereas for women the largest increase is beyond age $65 .{ }^{23} \mathrm{Pharmacologic}$ management of cholesterol abnormalities in the elderly using HMG CoA reductase inhibitors is becoming the preferred choice of treatment owing to the dependable efficacy and excellent tolerability of these drugs, the undesirable side effects of other therapeutic agents, and the difficulties in maintaining a balanced low-cholesterol, low-fat diet in this population. ${ }^{24}$

Controversy remains regarding the use of pharmacolngic agents in the management of hypercholesterolemia in the elderly, despite increasing evidence of the association of serum cholesterol and CHD in this population. Although early data from Framingham demonstrated no association of Total-C with coronary events in subjects over age 65 years, ${ }^{25}$ subsequent analyses have shown a direct relationship of $\mathrm{LDL}-\mathrm{C}$ values and an inverse relationship of HDL$\mathrm{C}$ levels to the occurrence of coronary events in the elderly. ${ }^{26}$ The most recent review of the Framingham data on the elderly population suggested that elevated Total-C remains a significant risk factor in older patients and that this relationship is stronger for women than for men. ${ }^{27}$ The Honolulu Heart Program, which studied a cohort of men of Japanese ancestry, has reported an association of coronary events with elevated serum cholesterol values in men 65 to 75 years of age. ${ }^{5}$ The Coronary Heart Disease in the Elderly Study by the Kaiser Permanente Medical Care Program concluded that increased serum cholesterol is directly associated with CHD mortality in elderly men. ${ }^{28}$ Finally, the trend toward decreased mortality from coronary disease from 1961 to 1983 has been shown in the elderly as well as in the younger populations. ${ }^{29}$ Thus, although differences of opinion still exist, the majority of the clinical evidence at this time supports the premise that elevated serum cholesterol is an important risk factor for $\mathrm{CHD}$ in the elderly.

Although the relative risk of CHD morbidity and mortality from hypercholesterolemia may be somewhat lower in the elderly than in the younger popu- lation, the prevalence, and therefore the attributable risk, is high. Denke and Grundy suggest an assessment of the relative risks and benefits as well as consideration of the individual's overall health status and competing risks prior to administering cholesterollowering therapy to elderly patients. ${ }^{24}$ As concluded by Bilheimer, the elderly are likely to benefit from risk factor reduction, and decisions on treatment for elevated cholesterol levels should not be made simply on the basis of age but should also consider the presence and severity of other diseases; the patient's mental status, and his or her expectations from medical care ${ }^{30}$ In clinical practice, the elderly patient with vascular disease is often very aware of the importance of cardiovascular risk factor control and will be greatly concerned about elevated cholesterol levels. If patients over the age of 65 years have a demonstrated vascular abnormality, such as coronary, carotid, or peripheral vascular disease, and also have elevated lipid levels, then strong consideration of pharmacologic treatment is indicated, especially if they are otherwise in good health.

In this study, pravastatin was effective in significantly reducing the levels of $\mathrm{LDL}-\mathrm{C}$, Total-C, and TG in elderly subjects with hypercholesterolemia. Pravastatin was also effective in raising HDL-C levels from baseline. These lipid effects observed with pravastatin treatment at an average daily dose of approximately $20 \mathrm{mg}$ are comparable to those reported in several other clinical trials involving primarily younger subjects. ${ }^{78}$ Advancing age does not appear to have an impact on the efficacy of pravastatin. In addition, pravastatin exhibited a high degree of safety and was well tolerated during extended treatment in these older patients, as has previously been reported to be the long-term experience of the drug in younger paticnts. ${ }^{9}$ In conclusion, long term pravastatin therapy was successful in improving the lipid profile of this elderly population without appreciable adverse effects.

\section{ACKNOWLEDGMENTS}

The authors wish to acknowledge the assistance of Suzette Abatto, Dorothy Conway, and Gabriella Cucinotta in the conduct of this study, of Jong-Soon Park in the performance of statistical analyses of the data, of Leo R. Maestripieri and John Keogh in the preparation of the manuscript, and of Marcia Maguire for her secretarial assistance.

\section{REFERENCES}

1. Steinberg $\mathrm{D}$. The cholesterol controversy is over. Why did it take so long [editoriall? Circulation. 1989;80:1070-1078.

2. Task Force on Cholesterol Issues, American Heart Assuciation. The cholesterol facts: a summary of the evidence relating dietary facts, serum cholesterol, and coronary heart disease. A joint statement by the American Heart Association and the National Heart, Lung, and Blood Institute. Circulation. 1990;81:1721-1733.

3. The Expert Panel. Report of the National Cholesterol Education Program Expert Panel on Detection, Evaluation, and Treatment of High Blood Cholesterol in Adults. Arch Intern Med. 1988;148:36-69. 
4. Grundy SM, Goodman DS, Rifkind BM, Cleeman JI. The place of HDL in cholesterol management: a perspective from the National Cholesterol Education Program. Arch Intern Med. 1989;149:505-510.

5. Benfante $R$, Reed D. Is elevated serum cholesterol level a risk factor for coronary heart disease in the elderly? JAMA. 1990;263:393-396.

6. Castelli WP, Wilson WF, Levy D, Anderson K. Cardiovascular risk factors in the elderly. Am J Cardiol. 1989;63:12H-19H.

7. Hunninghake $\mathrm{DB}$, Knopp RH, Schonfeld G, et al. Efficacy and safety of pravastatin in patients with primary hypercholesterolemia, I: a doseresponse study. Atherosclerosis. 1990;85:81-89.

8. Hunninghake DB, Mellies MJ, Goldtierg AC, el al. Efficacy and safely of pravastatin in patients with primary hypercholesterolemia, ll: once-daily versus twice-daily dosing. Atherosclerosis. 1990;85:219-227.

9. McGovern, ME, Mellies, MJ. Long-term experience with pravastatin in clinical research trials. Clin Ther. 1993;15:57-64.

10. Reihnér E, Rudling M, Stăhbberg D, et al. Influence of pravastatin, a spccific inhibitor of HMG-COA reductase, on hepatic metabolism of cholesterol. NEMM. 1990;323:224-228.

11. Tsujita Y, Kuroda M, Shimada Y, et al. CS-514, a competitive inhibitor of 3 hydroxy-3-methylglutaryl coenzyme A reductase: tissue-selective inhibition of sterol synthesis and hypolipidemic effect on various animal species. Biochim Biophys Acta. 1986;877:50-60.

12. McTavish D, Sorkin EM. Pravastatin: a review of its pharmacological properties and therapeutic potential in hypercholesterolaemia. Drugs. 1991;42:65-89.

13. Jones PH, Farmer JA, Cressman MD, et al. Once-daily pravastatin in patients with primary hypercholesterolemia: a dose-response study. Clin Cardiol. 1991;14:146-151.

14. Rubenfire $M$, Maciejko JJ, Blevins RD, et al. The effect of pravastatin on plasma lipoprotein and apolipoprotein levels in primary hypercholesterolemia. Arch Intern Med. 1991;151:2234-2240.

15. Davignon J, Roederer G, Hayden M, et al. Comparative efficacy and safety of pravastatin, nicotinic acid, and the two combined in patients with hypercholesterolemia [abstract]. In: Abstract Book of the 9th International Symposium on Atherosclerosis, Rosemont. III., 6-11 October 1991. Rosemont, III.: International Atheroscierosis Society, 1991: 261.

16. Yoshino G, Kazumi T, Uenoyama R, et al. Effect of eptastatin (CS-b14) on hypercholesterolemic patients: comparison with probucol. Curr Therap Res. 1986:40:1017-1021.

17. Goto $Y$, Yasugi T, Goto $Y$, et al. Clinical evaluation of CS-514 (pravastatin) on hyperlipidemia: double-blind study with clinofibrate [in Japanese, with English abstract]. Clin Eval. 1988;16:211-249.
18. Crepaldi $G$, Baggio $G$, Arca $M$, et al. Pravastatin vs gemfibrozil in the treatment of primary hypercholesterolemia: the Italian Multicenter Pravastatin Study I. Arch Intern Med. 1991;151:146-152.

19. Arntz H-R, Bînner G, Kikis D, et al. Efficacy of pravastatin and bezafibrate in primary hypercholesterolaemia [in German, with English abstract]. Dtsch Med Wochenschr. 1991;116:7-12.

20. Wiklund 0 , Angelin B, Fager $G$, et al. Treatment of familial hypercholesterolaemia: a controlled trial of the effects of pravastatin or cholestyramine therapy on lipoprotein and apolipoprotein levels. J Intern Med 1990;228:241-247.

21. The Lipid Research Clinics Population Sudies Data Book. Vol 1. Bethesda, MD: U.S. Department of Health and Human Services, Public Health Service, National Institutes of Health; 1980. Report No.: NHH-80-1527.

22. Delong DM, DeLong ER, Wood PD, et al. A comparison of methods for the estimation of plasma low- and very low-density lipoprotein cholesterol. The Lipid Rescarch Clinic Prcvalence Study. JAMA. 1986;256:2372-2377.

23. Grundy $S M$, Greenland $P$, Herd $A$, et al. Cardiovascular and risk factor evaluation of healthy American adults: a statement for physicians by an ad hoc committee appointed by the Steering Committee, American Heart Association. Circulation. 1987;75:1340A-1362A.

24. Denke MA, Grundy SM. Hypercholesterolemia in elderly persons: resolving the treatment dilemma. Ann intern Med. 1990;112:780-792.

25. Gordon T, Castelli WP, Hjortland MC, et al. High density lipoprotein as a protective factor against coronary heart disease: the Framingham study. Am J Med. 1977;62:707-714.

26. Cupples LA, D'Agostino RB. Some risk factors related to the annual incidence of cardiovascular disease and death using pooled repeated biennial measurements: Framingham Heart Study, 30 year follow-up. In: Kannel WB, Wolf PA, Garrison RJ, eds. The Framingham Study: An Epidemiologic Investigation of Cardiovascular Disease, Section 34. Washington, DC: U.S. Department of Health and Human Services, National Institutes of Health; 1987: 31, 221, 448. Report No.: NHH-87-2703.

27. Harris T, Cook EF, Kannel WB, Goldman L. Proportional hazards analysis of risk factors for coronary heart disease in individuals aged 65 or older: the Framingham Heart Study. J Am Geriatr Soc. 1988;36:1023-1028.

28. Rubin SM, Sidney S, Black DM, et al. High blood cholesterol in elderly men and the excess risk for coronary heart disease. Ann Intern Med. 1990;113:916-920.

29. Walker WJ. Changing U.S. life style and declining vascular mortality: a retrospective [editorial]. NEJM 1983;308:649-651.

30. Bilheimer DW. Clinical considerations regarding treatment of hypercholesterulernia in the elderly. Atherosclerosis. 1991;91:S35-S57. 